\title{
Managing digital coordination of design: emerging hybrid practices in an institutionalized project setting
}

Article

Accepted Version

Whyte, J. (2011) Managing digital coordination of design: emerging hybrid practices in an institutionalized project setting. Engineering Project Organization Journal, 1 (3). pp. 159-168. ISSN 2157-3735 doi:

https://doi.org/10.1080/21573727.2011.597743 Available at https://centaur.reading.ac.uk/21390/

It is advisable to refer to the publisher's version if you intend to cite from the work. See Guidance on citing.

To link to this article DOI: http://dx.doi.org/10.1080/21573727.2011.597743

Publisher: Taylor \& Francis

All outputs in CentAUR are protected by Intellectual Property Rights law, including copyright law. Copyright and IPR is retained by the creators or other copyright holders. Terms and conditions for use of this material are defined in the End User Agreement.

\section{www.reading.ac.uk/centaur}


Central Archive at the University of Reading

Reading's research outputs online 


\title{
Managing Digital Coordination of Design:
}

\section{Emerging Hybrid Practices in an Institutionalized Project Setting}

\author{
Jennifer Whyte \\ Design Innovation Research Centre, School of Construction Management and Engineering, \\ University of Reading, UK.
}

Tel: +44 1183785228

j.whyte@ reading.ac.uk

Author copy, please cite the published version:

Whyte, J. (2011) Managing digital coordination of design: emerging hybrid practices in an institutionalized project setting. Engineering Project Organization Journal, 1 (3), pp. 159-168.

http://dx.doi.org/10.1080/21573727.2011.597743

The final, definitive version of this paper has been published in Engineering Project Organization Journal, 1/03, 2011 by Taylor and Francis Ltd, All rights reserved. () This is the accepted version, posted by the first author on the University of Reading website under the terms of the contributor agreement. Please cite the published version and refer to it for pages, etc.

\section{Acknowledgements:}

The author would like to thank the managers and engineers on the project; the editor and anonymous reviewers; reviewers and participants at the CIB World Congress 2010 in Salford, UK where an early version was presented; and colleagues Chris Harty and Sunila Lobo, who were involved in the set-up meeting. The various stages of this research have been supported through EPSRC awards no. EP/H02204X/1 and EP/E001645/1; and ESRC award no. RES-331-27-0076. The author retains full responsibility for this work and its presentation in the final text. 


\title{
Managing Digital Coordination of Design:
}

\section{Emerging Hybrid Practices in an Institutionalized Project Setting}

\begin{abstract}
What happens when digital coordination practices are introduced into the institutionalized setting of an engineering project? This question is addressed through an interpretive study that examines how a shared digital model becomes used in the late design stages of a major station refurbishment project. The paper contributes by mobilizing the idea of 'hybrid practices' to understand the diverse patterns of activity that emerge to manage digital coordination of design. It articulates how engineering and architecture professions develop different relationships with the shared model; the design team negotiates paper-based practices across organizational boundaries; and diverse practitioners probe the potential and limitations of the digital infrastructure. While different software packages and tools have become linked together into an integrated digital infrastructure, these emerging hybrid practices contrast with the interactions anticipated in practice and policy guidance and presenting new opportunities and challenges for managing project delivery. The study has implications for researchers working in the growing field of empirical work on engineering project organizations as it shows the importance of considering, and suggests new ways to theorise, the introduction of digital coordination practices into these institutionalized settings.
\end{abstract}




\section{Introduction}

Digital technologies have a profound effect on the nature and structure of organizations (Kallinikos 2006). They play a significant role in the reorganization of many broad sectors of the economy, with research describing changes in healthcare (Martin et al. 2006); aerospace (Berente and Yoo 2007); pharmaceuticals (Nightingale 2000), and computer hardware design (D'adderio 2003). In engineering project organizations, Levitt and Whyte (2011) argue that new digital practices are breaking the mold of 1960s approaches to project management, with the emergence of both highly structured centralized systems, for example, the digital integration of information in construction through 'Building Information Modeling' (BIM) (Eastman et al. 2008); and the simultaneous emergence of decentralized social networking or Web 2.0 approaches.

Researchers are now beginning to draw on organization studies and sociology to theorise digitally-enabled design work on construction projects (Harty 2005, Boland, Lyytinen and Yoo 2007, Hartmann and Fischer 2007, Taylor 2007, Bresnen and Harty 2010, Dossick and Neff 2010, Harty and Whyte 2010, Tryggestad, Georg and Hernes 2010, Whyte and Lobo 2010). Boland et al. (2007), for example, track innovation on a project by the architect Gehry, arguing that use of three-dimensional (3D) digital technologies allows waves of innovation to propagate across the firms involved. Taylor (2007) identifies factors that form pre-conditions (work allocation, interdependence, current technology); that affect implementation (alignment of the innovation to project network, firm interests) and that affect acceptance (relational stability, interests, boundary permeability, an agent for change). Dossick and Neff (2010) focus on the coordination of Mechanical Electrical and Public Health (MEP) services and posit that leadership skills enable managers in design and construction organizations to deal with the increasing tight coupling of technological 
solutions within loosely coupled organizational structures. Hence work in this field seeks to increases understanding of digital practices in engineering project organizations from a variety of theoretical perspectives. It provides rich empirical detail and new ways to theorise consequences of new technologies, factors involved in implementation; and the demands they place on organizational leaders, however, it has paid only limited attention to how highly institutionalized contexts shape the practices that emerge.

Questions about how technologies become used in institutionalized project settings are timely, as there is rapid uptake of digital practices in sectors such as construction, with a recent study in the USA, for example, noting that in 2009 half of contractors are using digital models, a 75\% increase in usage in 2 years (Young et al. 2009). Procedures for digital design and construction are being written into public procurement in countries such as Sweden, Denmark, Norway and the USA (Gsa Deca Senaatti Statsbygg 2007). In the UK, there is a standard that defines methods for the management of production, distribution and quality of construction information (Richards 2010); with recent government strategy including targets for progressively mandated use of collaborative Building Information Modelling for government projects. Studies of innovation have tended to focus on such novelty rather than technology-in-use (Edgerton 2007), and hence have under-represented the hybrid forms that arise as new tools become implemented; the multiple uses and the potential growth in significance of technologies as they become enmeshed in practices. In the context of digital coordination practices there is little understanding of the diversity of organizational practices that are emerging beyond those recommended in industry and policy guidance.

This paper focuses on the question: "What happens when digital coordination practices are introduced into the institutionalized setting of an engineering project?" It draws on an interpretive study that examines how a shared digital model becomes used in the late design 
stages of a major station refurbishment project. The implementation of such a shared digital model involves repositories for digital data; standards and protocols for the use of this data and a wide suite of CAD modeling and simulation software packages and tools (Whyte and Lobo, 2010). The rationale behind this integrated set of practices is now often described as Building Information Modeling (BIM) (Eastman et al. 2008, Dossick and Neff 2010). As software tools and packages are become linked together, with each other, and with the implementation of new practices; organization scholars have begun to theorise their role as 'infrastructure' (Edwards et al. 2007) rather than separate 'objects' or 'packages'. In this paper the shared model is thus discussed theoretically as 'digital infrastructure', to emphasise the interlinked nature of the digital systems and the central role they increasingly play in design coordination practices.

The next section gives a description of the project setting, and the data collection and analysis processes. The findings are then summarised and discussed in two following sections. These articulates the diverse patterns of activity that emerge: 1) as, within the project team, professions develop different relationships with the shared model; 2) as the project team negotiates paper-based practices across organizational boundaries, using the shared model for the design work within the team and generating traditional deliverables for the client, local authorities and regulators; and 3) as diverse practitioners probe the potential and limitations of the digital infrastructure.

Interpretative research aims to expose the reader to the rich detail of the case, and to use this to develop new theoretical insight (Dougherty 2002) so the paper draws in existing literature to develop the argument through the analyses and interpretation of the data rather than presenting it separately before describing the study. The study has implications for researchers working in the growing field of empirical work on engineering project 
organizations as it shows the importance of considering, and suggests new ways to theorise, the introduction of digital coordination practices into these institutionalized settings. The discussion section considers how hybrid practices emerge around the digital infrastructure that involve patterns of loose as well as tight coupling and how these contrast with the more direct interactions anticipated in practice and policy guidance. The conclusions section articulates the implications for further research, showing how the emerging hybrid practices within institutionalized project settings raise important new questions about digital coordination in engineering project organizations.

\section{Research Setting and Design}

\subsection{The Station Refurbishment Project}

The case study that is analysed and discussed is a major station refurbishment. The work includes upgrades to the platforms, a services building, enlarged ticket hall and entrances, all for a tightly constrained site located at one of the busiest junctions in a major European capital. There are many physical interdependencies as well as tight project deadlines. Objectives include step-free access, station modernisation and fire safety improvements; and hence the design work provides congestion relief / capacity enhancement; additional escalators; additional connections to platforms and improved interchange.

While the initial design was developed by a different team, the engineering design consultancy with which this study was conducted was engaged at detail design stage to lead a multi-disciplinary team that would develop the design further and produce contract documentation. Their work on the scheme involves interaction with government bodies including the Highways Authority, and local boroughs. The team consists of tunnels, 
structures and mechanical, electrical and public health (MEP) engineers; with subcontractors including two architectural firms; and engineers from the client. The previous scheme design, which they inherited, was drawn up in 2D drawings. However, the managers decided to develop the design in models rather than drawings because of the complex $3 \mathrm{D}$ nature of the work: at a junction located in an area with high volumes of pedestrian and vehicle traffic and design work on new facilities that join onto existing infrastructure, connecting with 19th century tunnels and spanning across different levels, above and below ground, and at times under existing buildings.

Sharing of data is achieved through two software packages, from a major software provider, which provides similar products to its competitors. This embeds the use of off-the-shelf packaged software solutions into the core of the delivery processes associated with the project. The packages, which are configured so that they are always used simultaneously, include:

- ' $C A D$ ' - the base Computer Aided Design (CAD) package, used for both 3D modeling and the 2D drafting work.

- 'Coordination' - the repository, in which CAD data is stored, versions are managed and workflows are applied.

The 'coordination' software takes substantial work to set-up for the project, while the CAD package is used more as an off-the-shelf package, supplemented with the software provider's wider suite of add-on packages, with a specialist 3D modeling tool and structural, mechanical and electrical tools for the various disciplines; a package for highways design and for the reinforced concrete (RC) detailing. A separate provider's viewing software is used for viewing 3D files and for clash detection. 
For the project managers, and other professionals working on the project, a major benefit of working in a shared 3D model is the ability to co-ordinate the designs of different specialists, particularly important in the mechanical, electrical and public health (MEP) design; and in co-ordinating these services with the structures. Staff working on the project bring significant experience from a wide range of other infrastructure projects as well as from other industries such as automotive and petrochemical. However, for the team as a whole, as well as for a number of the engineers, CAD technicians and architectural designers, the project was their first experience in using 3D for design across all disciplines and project areas. Project managers note how the work on the project involves complex transfers of information and data in which teams are mutually dependant; uncertainty exists surrounding the design problem and potential solutions; and the problem is understood by speculating and testing design solutions. The design work is conducted at the end of a boom in construction where there are real challenges getting staff into some roles.

The office in which the design work was conducted, and in which the researcher was located when conducting fieldwork, is open-plan, above the site, with views down over it. The various disciplinary teams sit together and the central corridor through the office contain cardboard models of the enlarged station, with color 3D print outs on the wall near the entrance to the office. Around the corner, beyond the coffee area, there is a wall that contains management information, including printed out schedules, with ink marks showing how progress is tracked against them; and risk registers for the various aspects of the design. The engineering teams work-full time in these offices. The architects are based part-time here, spending a few days a week back in their home offices. The client has some staff that work in this office alongside the team. 


\subsection{Data Collection and Analysis Methods}

Data was collected during days spend in the project office where the team were collocated. Interviews enabled the researcher to understand the novel aspects that become introduced with the use of the shared model and the challenges encountered. Being located in the project office and able to observe practice was important to see the range of tools that allow practitioners to accomplish their jobs. The study is interpretive (Silverman 1997, Dougherty 2002, Walsham 2006), and hence rather than seeking statistical generalizability; it aims to build theoretical understanding of the phenomenon of study, in this case digital coordination in institutional settings, by drawing on the observations in a particular place or time, in such a manner that this theory may be used to understand the same phenomena in other places and times. Hence the focus is on the quality, rather than the quantity, of data; and on its interpretation. There is also a recognition that the researcher is a major instrument in this work of data collection and interpretation, and that they always learn through the process of the research. In this study, the researcher started out with substantial previous experience of research in related contexts which helped in rapidly focusing attention on the characteristic features of the case; but extended and deepened understanding through this work.

The fieldwork was conducted over a six month period; bounded by the beginning and end of a late design stage, involved in the preparation of 'production information' (August 2008 to December 2008), though the researcher had started visiting the project as the report for the previous stage 'detailed design' was prepared (May to July 2008). To give an overview of the project, there was an initial two hour meeting with the project manager, design manager, $R \& D$ director and rail director from the engineering design consultancy in May; and materials relating to the project were provided then. The researcher was able to organize a pass and desk to spend days in the project offices through the production information stage 
talking to the different professionals within the team about the ongoing work and conducting more formal semi-structured interviews with key members of the project team. The first point of contact was the project administrator, and by visiting the project every 3-4 weeks during the stage the researcher also established an ongoing relationship with the project manager, design manager and CAD manager and other key members of the team. These professionals were interested in the research and highly reflective about their own digital practices and how they could be improved; interacting with the researcher formally and informally by email; over coffee and in meetings.

The 13 semi-structured interviews involved the project manager, design manager, project administrator, CAD manager, document controller, structures engineer, structures modeler, three architects, tunnels engineer, MEP modeler and client project manager. The research uses a well-developed interview protocol that has been used across a number of case studies (e.g. author date), with interview questions about digital packages, learning and the effectiveness of processes and systems. Interviews ranged from 40 minutes to one hour were often conducted at people's desks within the office. Their semi-structured nature allow participants to talk more broadly about their interpretations and experiences of using the shared digital model in their work, but also gave the researcher a structure to hone in on the topics of interest to the research around design coordination. As the interviews progressed, the focus was sharpened and hence in the later interviews the topics that emerged as important in preliminary analyses were probed in more detail. As interviews were conducted in the open plan office the interviews were not all taped [3.5 hours of material were taped and transcribed]. The focus was on building the trust of the participants and in taking detailed notes to capture both their and the researchers understandings. A benefit of the location was that interviewees demonstrated issues by turning to their computer and showing the 
researcher aspects of their work. Although these more formal interviews were set up by appointment in advance on two occasions interviewees had also invited a colleague to join the conversation, and this sparked further useful information about the digital practices for design coordination.

Interpretative research emphasises this value of becoming 'engaged' (Van De Ven 2007), closely involved in the activities that are being studies and seeking to develop new understanding of these observed phenomena (Walsham 2006). Hence, the data analysis phase overlapped with the data collection, as field notes were typed up and reread and the taped interviews were transcribed and read between days in the project. There was iteration between the focus on empirical data and literature, with summaries of interviews being sent back to participants to check and theory relating to the empirical phenomena also being explored at this stage. While software was used to track themes across the interviews, the analysis employed strategies appropriate for analysing process, rather than variance, data (Langley 1999), with most analytic time spent rereading notes and synthesising findings by writing narratives about the case. First these were organized into a set of descriptive narratives that covered aspects of the organizational structure and processes for achieving design coordination, with topics from the protocol such as the use of the shared model, learning and effectiveness, and then these were further refined, reorganized and theorised. An early set of narratives were provided to the team in a 12 page summary format and this summary was discussed in detail with project managers, who spent two hours going through the document with the researcher. This exercise helped the researcher correct factual errors and provided further data focused on the emerging themes. As is common in interpretive research, the final theoretical framing, which is described in the following sections, was developed through such analytical work. Throughout the analysis and writing process, 
emerging theoretical ideas raised new questions about interpretation and there was a constant process of returning to the source data and literatures for clarification and to develop and extend explanations.

\section{Relationships with the Shared Model}

There is a strong contrast between the way that divisions of labor between design and modeling have become institutionalized in the architecture team and the engineering teams in this setting. Institutional theorists suggest that multiple professions in a mature institutional context have deeply rooted disciplinary practices and draw on diverse cultures, meanings and values (Ferlie et al. 2005, Greenwood and Suddaby 2006, Scott 2008). This is apparent in the way that professionals in this setting make sense of the introduction of a shared model. Architects do their own drawing and modeling work, whereas in engineering, engineers have become used to handing calculations, sketches and instructions to CAD technicians that work alongside them. Such distinctions have been studied at the time of the introduction of CAD drafting tools (Schaffitzel and Kersten 1985, Currie 1989, Henderson 1999). This division of labor is replicated around the digital model and hence the allocation of responsibilities within the sub-teams is shown in Figure 1. The boundaries between software packages indicate organizational boundaries, with the architects and engineering $\mathrm{CAD}$ specialists using the 'CAD' and 'Coordination' packages with specialist add-on solutions relevant to their discipline.

$<<$ Insert Figure 1 >> 
The engineers' lack of direct experience with the system weakens their sense of the digital infrastructure providing a shared model, or of it being centrally located between the different designers. The idea of a shared model in design coordination is not new (e.g. Anumba et al. 2000), but the implementation in this institutionalized environment substantially more organizationally elaborate than the more simple configuration anticipated in the early research and policy documents - which envisioned each professional located around the shared model; as replicated for example in Smith and Tardiff (2009: Figure 0.1, page xx). Architects have direct access to the shared model, and use it directly in their work, but they do not find themselves interacting with engineers that have a symmetrical relationship with it.

The plan, within the engineering disciplines (structures, MEP and tunnels), was to have one 3D modeler per discipline area and to use the 3D model to take extractions, and produce drawings. This gives would give one person the ownership of modeling the engineering design work of each disciplinary group. However, in practice this also causes a bottleneck in the work process, as modeling skills were in demand (and hence expensive as difficult to replicate) during the period studied (partly because of the construction boom), and the project team did not have a modeler in place in each disciplinary team throughout the stage observed. As the project CAD manager notes:

You find that it's all well and good saying you want it in 3D, but you have also got to have the people who can use and think in 3D. I find a lot of CAD designers, CAD users are not experienced in it. Don't know how to use the software. (CAD manager)

Within engineering, this process of creating 3D models also presented new difficulties in motivating 2D CAD technicians. The engineering teams all included both 3D modelers and 2D CAD technicians, with for example, one modeler and three to four technicians in the tunnel engineering discipline. The $2 \mathrm{D}$ CAD technicians take the extraction created by the 3D 
modeler and add any additional required line-work. They are not involved in the set-up, or as involved in actively thinking through the construction details; and as a result can lack a sense of fulfillment in their roles. Across the project:

We have a team of 2-3 modelers that are basically modeling everything and they extract all the plans and sections that then go to the 2D CAD technicians to put together on drawings. The only draw-back of this is that the guy putting the drawing together doesn't have any real involvement in the design of something. (CAD manager)

During the period studied, the scarcity and status of 3D modelers was also seen as a problem by managers. For example:

Some of them think they are too good to do the basic model. (CAD manager)

Within the project, there was an expectation that everyone would do everything, picking up the work of others to deliver design work by the agreed deadlines, but the elevated status of modelers meant they brought a new set of expectations to their role.

\section{Organization Boundaries and Emerging Hybrid Practices}

The processes observed in this project are significantly different from those proposed in policy documents, such as the standard methods (Richards 2010), as they involve the conversion of the model back into 2D drawings ahead of the approvals and deliverable signoff process. Although the project team is committed to a model-centric approach to design, the wider system within which they operate is institutionalized around 2D plans and sections, and they are still required to produce these for approval from regulatory bodies and as a deliverable to the client. To accommodate this, hybrid practices emerge. 
Such practices bring together digital and physical media through a variety of formalized and improvised practices as 'plugging' and 'patching' takes place across ecologies of practice to enable the ongoing accomplishment of work (Harty and Whyte 2010). In the workflows within each of the engineering disciplines in the project team, new practices emerge after the modeler works with the engineer to model the design, as these models are then extracted to plans and sections that go to CAD technicians to develop into the drawings. Details are then added to the $2 \mathrm{D}$ drawings before issue. Design work is thus conducted using a combination of $2 \mathrm{D}$ and $3 \mathrm{D}$, with all the $2 \mathrm{D}$ plans and sections coming from the $3 \mathrm{D}$ model. The release of information to the client and the various regulatory bodies requires it to be checked, verified and approved, and the workflow is summarised below in Figure 2.

$<<$ Insert Figure 2>>

Approximately 3000 drawings and documents need to be approved at the end of each stage, so in preparing the production information, the team, which had been involved since the detail design stage, was managing a project that involved 10,000 records. A 'document controller' ensures that no work goes out from the team without having been through the process. Before information is released to the client, and then archived, engineers and managers should check the data and document controllers approve its release.

In effect only the work-in-progress of each discipline is in $3 \mathrm{D}$, so it becomes hard for some teams to keep the whole progress 'in synch' as changes made by engineers in the checking and approval process get made on drawings, developed by the 2D CAD professionals and have to be put back into the model by the 3D CAD professional. The 'Coordination' package 
shows the workflow for each part of the model, and for each drawing that comes from the model. Within it, drawings have different statuses: work-in-progress (WIP); designer check; coordination check; manager approval; approved and issued. A major challenge discussed in interviews was that modeling in 3D takes 'a lot longer', but the team is working to the 'same time-scales as 2D'. Hence, according to an interviewee, this new way of working has longterm benefits, reducing errors on site, but there is extra work to get to the $2 \mathrm{D}$ plans. It is a 'larger process' but is 'worth it in the end.'

The change from institutionalized understandings of the length of different stages of work raises additional challenges. The new processes present managers with little visibility of the completeness of the design work represented in models and drawings. This makes it difficult for them to manage client expectations, especially where the completeness of design may have contractual implications. The client manager, who was relatively new in his organization, had a perception that:

They have delivered all their work in $2 \mathrm{D}$, just basic $2 \mathrm{D}$ plans and sections and now they are doing the modeling after they have produced the drawings. (client manager)

3D modelers and 2D CAD professionals also commented that they found it more difficult to estimate timescales; when sometimes they are asked to do things they:

'don't know how to do [them] so don't know how long [these things] will take.' (CAD technician)

This is a particular problem around stage deadlines, and one example given was that at the detail design deadline, when adding annotations to drawings, which should have been a five minute job, took half a day. 
As 3D information takes longer to produce than 2D information and the process involved coordinating the work of a larger number of professionals, one interviewee estimated that the production of a drawing took 3-6 weeks to the final 2D drawings using the new processes whereas it would have taken 2 weeks to draw on a 2D basis. Another estimated that it takes a week to do what would have taken a couple of days to do on a 2D basis. On previous stages, such as detail design, resources issues, particularly difficulty obtaining and retaining 3D modelers and the departure of a services sub-consultant, meant the model was dropping behind design work except where there were changes that affected others.

\section{Digital Infrastructure and New Practices}

An ongoing process of modifying both practices and infrastructure was apparent around some limitations identified in their use of the ' $C A D$ ' package that mean it takes extra work to get 2D plans and is not just a slice through the model. The team was using the electrical/mechanical software solution that is an add-on to the basic ' $C A D$ ' package for the first time. When they piloted and tested it they came across issues with the maturity of this software solution. The specialist functions supporting mechanical engineering design functioned well, but those supporting electrical design were not adequate. The software was:

90\% complete and updating, [it] can't do what [it] says on tin. (CAD Manager)

This was particularly challenging as the work 'involves processes outside of core design.' Another example was a problem with the viewing software, which could not accommodate partial updates to a model, so changes in the model needed to be re-imported and the clash detection needs to be done from scratch again. 
The 'Coordination' software package also had teething problems and was overly complex though useful. One interviewee described such generic software bugs as: 'ghosts in the machine', explaining that there were changes people thought they have done ahead of a previous deadline that were not there in the system. The 'Coordination' package leaves an audit trail, but a number of interviewees pointed to issues with information going missing and corrupt files, or to problems with visualizing data as the ability to print out from the system was not set up. One felt it needed a lot of customization and the Windows folder structure would be easier to use, although this would not have had the advantage of tracking file changes.

Across the team there is significant interest in process improvement, and while this created wakes of innovation (Boland, Lyytinen and Yoo 2007), this was not free flowing, but rather accomplished through careful attention to the nature and effectiveness of the range of emerging hybrid practices, and significant trial and error with the digital infrastructure. Some ideas were implemented through the development of new software solutions, for example the document controller describes the implementation of new practices on the project where they:

Happened to have an Access database developer - used her to set up a system for document tracking. (document controller)

Other the ideas were just proposed, or dreamed of, such as the idea of one member of the architectural team, who could see the value of setting parameters for tiling etc so that the design could be quickly changed by changing the parameters, but noted that:

I think that's great and I'd love to be able to - the problem with that I think is if I set it up, nobody else can do it. (architect) 
This idea was not implemented as the architect anticipated a potential problem, as any other architect that might take over their role at a later stage might not understand how to use a parametric model.

\section{Discussion: Hybrid Practices around Digital Infrastructure}

A challenge for researchers is to find new ways to interrogate and understand the profound effects that digital technologies are having on the nature and structure of engineering project organizations. This study shows how the configuration of digital infrastructure, and the hybrid practices that emerge when it is implemented, become important in design coordination. In the project studied, management challenges related to process or performance management become salient. The team was under pressure to deliver to traditional timescales though it took longer to develop 3D information that could then add benefit at later stages. The digital infrastructure for delivery challenges understandings of the activities in and duration of different stages of the design process; and the deliverables each stage should produce. Within the project, it became difficult to find effective 3D modes of working without changing wider institutionalized practices.

To provide practical guidance to managers, there is a need for further research to expand the examination and theorization of the hybrid practices that emerge as new digital infrastructure is used in the context of institutionalized practices. The literature on institutional theory has informed this study, as well as other work on engineering project organizations (Mahalingam and Levitt 2007). Recent work on socio-material practice and complex organizations suggest alternative starting points for this theoretical work, and these are discussed briefly here, drawing on the study and with reference to engineering project organizations. 
First, the idea of sociomaterial practice is invoked in the phrase 'ghosts in the machine', introduced by an interviewee within the station project ${ }^{1}$. The inextricable nature of the social and the technical has been the focus of recent research attention within organization studies and information systems (e.g. Orlikowski 2007, 2010). In the emergent hybrid practices that evolve around digital infrastructure in the station project, the material nature of the tools with their software bugs and issues raises issues for practice. One interpretation may be that this is an issue of implementation, something that will be worked out in later version of the tools. For any one tool that may be the case, but here instead the interpretation is that, resonant with this wider literature on practice, innovative practices always involves these workarounds and compromises. Hence to focus on understanding these is of ongoing relevance to our understanding of the emerging hybrid practices of design coordination.

Second, the literatures on complex organizations indicate paradoxical and incompatible requirements for tight coupling to deal with interdependencies ahead of time and loose coupling to deal with the exceptions arising in ongoing operations (Perrow 1999 [1984]). A number of scholars particularly highlight organizational benefits to 'loose coupling' between elements of organization, where these elements are responsive but retain separateness and identity (Weick 1976, Orton and Weick 1990). In the station project, the emerging hybrid practices result in radically different patterns of loose and tight coupling in different areas of the project. This differs from Dossick and Neff's (2010) discussion of an MEP case, in which they contrasts loose organizational coupling, seen as characteristic of the construction industry, with tight technical coupling, seen as characteristic of the digital coordination

\footnotetext{
${ }^{1}$ The phrase references, perhaps unwittingly, Ryle's (1949) critique of Descartes mind/body dualism. The idea was later taken up by Koestler (1990 [1967]) who describes the human brain as developed on simpler material structures that act in such a manner that they are perceived without being consciously observed.
} 
technologies. The alternative socio-material explanation, favored here, is that the hybrid practices that emerge around the use of digital infrastructure involve patterns of both tightly and loosely coupled activities as attempts are made to embed new ways of working. Both studies begin to unpick the new forms of interaction and coupling that digital technologies enable (Kallinikos, 2006) with the potential for non-linear and multiple interdependencies between the different parts of engineering project organizations, and this is an area that demands further research attention.

The concepts in these literatures provide starting points for the further theoretical and empirical work needed to understand digital infrastructure in practice, to draw fine-grained research attention to how different professions structure their interaction with the integrated software, to examine how packaged software solutions and standardised packages become integrated to form digital infrastructures for delivery and, of particular concern to the projectbased firms engaged in engineering projects, to understand how commercial value is obtained in this evolving area of practice.

\section{Conclusions}

This work contributes to a trajectory of research on engineering project organizations, which, informed by organization studies and sociology, is developing fresh approaches to studying digital practices in engineering projects through empirical studies that use data to shape and develop theory. The questions that this study addresses, about how practices emerge within institutionalized project settings are important to understanding digital coordination in these contexts, as digital infrastructure is changing the nature of professional work and the organization of design in engineering projects. The paper contributes by mobilizing the idea 
of 'hybrid practices' to understand the diverse patterns of activity that emerge to manage digital coordination of design.

The relationships that emerge between the various professionals and shared digital model are not as symmetrical or as static as implied by idealised charts in industry and policy documentation. Document controllers, CAD managers, 3D modelers, 2D CAD technicians are among the new roles in the modern design office. The engineering project organization operates within a wider set of institutionalized practices, which include formats for delivery, building regulations, local authority permissions and construction schedules, and work-flows have to acknowledge the formats required for approvals and deliverables within this wider context.

This paper attempts to keep visible the physical context of the engineering project team's work, collocated in a project office above their station refurbishment site, while analysing the emergent digital practices. It articulates how engineering and architecture professions develop different relationships with the shared model; the design team negotiates paper-based practices across organizational boundaries; and diverse practitioners probe the potential and limitations of the digital infrastructure. A limitation of the work is the sole focus on the centralized systems that are being put into place in engineering projects; rather than the wide range of social networking and Web 2.0 software that is increasingly being used alongside such systems.

\section{References}

Anumba, C .J., Bouchlaghem, N.M., Whyte, J.K. and Duke, A. (2000) Perspectives on a shared construction project model. International Journal of Cooperative Information Systems, 9(3), 283-313. 
Berente, N. and Yoo, Y. (2007) Reconciliation Mechanisms and the Façade of Alignment with Enterprise Systems: The Case of NASA, in Academy of Management Conference, Philadelphia, PA, August 3-8.

Boland, R.J., Lyytinen, K. and Yoo, Y. (2007) Wakes of innovation in project networks: The case of digital 3-d representations in architecture, engineering, and construction. Organization Science, 18(4), 631-47.

Bresnen, M. and Harty, C. (2010) Editorial: Special issue on objects, knowledge sharing and knowledge transformation in projects. Construction Management and Economics, 28 (6): 549-55.

Currie, W.L. (1989) Investing in CAD: A case of ad hoc decision making. Long Range Planning, 22(6), 85-91.

D'Adderio, L. (2003) Configuring software, reconfiguring memories: The influence of integrated systems on the reproduction of knowledge and routines. Industrial and Corporate Change, 12(2), 321-50.

Dossick, C.S. and Neff, G. (2010) Organizational divisions in BIM enabled commercial construction. Journal of Construction Engineering and Management, 136(4), 459-67.

Dougherty, D. (2002) Building grounded theory: Some principles and practices, in Baum, J.A.C. (ed.), Blackwell Companion to Organizations, Blackwell Publishers, Oxford, pp. 849-67.

Eastman, C., Teicholz, P., Sacks, R. and Liston, K. (2008) BIM Handbook: A Guide to Building Information Modeling for Owners, Managers, Designers, Engineers and Contractors. Wiley, Hoboken, NJ.

Edgerton, D. (2007) The Shock of the Old: Technology and Global History since 1900. Profile Books / Oxford University Press, Oxford.

Edwards, P.N., Jackson, S.J., Bowker, G.C. and Knobel, C.P. (2007) Understanding infrastructure: Dynamics, Tensions, and Design. DeepBlue, Ann Arbor, MI.

Ferlie, E., Fitzgerald, L., Wood, M. and Hawkins, C. (2005) The nonspread of innovations: The mediating role of professions. Academy of Management Journal, 48(1), 117-34.

Greenwood, R. and Suddaby, R. (2006) Institutional entrepreneurship in mature fields: The big five accounting firms. The Academy of Management Journal, 49(1), 27-48.

GSA DECA Senaatti Statsbygg (2007) Statement of intention to support building information modeling with open standards, government clients of the aec/fm industry: Public statement. In: GSA, DECA, Senaatti, Statsbygg.

Hartmann, T. and Fischer, M. (2007) 3D/4D model supported visual knowledge distribution. Building Research and Information, 35(1), 70-80.

Harty, C. (2005) Innovation in construction: A sociology of technology approach. Building Research and Information, 33(6), 512-22. 
Harty, C. and Whyte, J. (2010) Emerging hybrid practices in construction design work: The role of mixed media Journal of Construction Engineering and Management, 136(4), 468-76.

Henderson, K. (1999) On Line and On Paper: Visual Representations, Visual Culture and Computer Graphics in Design Engineering. MIT Press, Cambridge, MA.

Kallinikos, J. (2006) The Consequences of Information: Institutional Implications of Technological Change. Edward Elgar, Cheltenham.

Koestler, A. (1990 [1967]) The Ghost in the Machine. Penguin Group, London.

Langley, A. (1999) Strategies for theorizing from process data. Academy of Management Review, 24(4), 691-710.

Mahalingam, A. and Levitt, R.E. (2007) Institutional theory as a framework for analyzing conflicts on global projects. Journal of Construction Engineering and Management, 133(7): 517-28.

Martin, D., Hartswood, M., Slack, R. and Voss, A. (2006) Achieving dependability in the configuration, integration and testing of healthcare technologies Computer Supported Cooperative Work, 15(5-6), 467-99.

Nightingale, P. (2000) Economies of scale in experimentation: Knowledge and technology in pharmeceutical R\&D. Industrial and Corporate Change, 9(2), 315-59.

Orlikowski, W.J. (2007) Sociomaterial practices: Exploring technology at work. Organization Studies, 28(9), 1435-48.

Orlikowski, W.J. (2010) The sociomateriality of organisational life: Considering technology in management research. Cambridge Journal of Economics, 34(1), 125-41.

Orton, J.D and Weick, K.E. (1990) Loosely coupled systems: A reconceptualization. Academy of Management Review, 15(2), 203-23.

Perrow, C. (1999 [1984]) Normal Accidents: Living with High-Risk Technologies. Princeton, New Jersey: Princeton University Press.

Richards, M. (2010) Building Information Management: A Standard Framework and Guide to $B S$ 1192, British Standards Institution, London.

Ryle, G. (1949) The Concept of Mind. Penguin Books, Harmondsworth, UK.

Schaffitzel, W. and Kersten, U. (1985) Introducing CAD systems. Problems and the role of user-developer communication in their solution. Behaviour and Information Technology, 4(1), 47-61.

Scott, W.R. (2008) Lords of the dance: Professionals as institutional agents. Organization Studies, 29(2), 219-38.

Silverman, D. (1997) Qualitative Research: Theory, Method and Practice, Sage, London. 
Smith, D.K. and Tardif, M. (2009) Building Information Modeling: A Strategic Implementation Guide for Architects, Engineers, Constructors, and Real Estate Asset Managers. London: John Wiley and Sons.

Taylor, J.E. (2007) Antecedents of successful three-dimensional computer-aided design implementation in design and construction networks. Journal of Construction Engineering \& Management, 133(12), 993-1002.

Tryggestad, K., Georg, S. and Hernes, T. (2010) Constructing buildings and design ambitions. Construction Management and Economics, 28(6), 695-705.

Van de Ven, A.H. (2007) Engaged Scholarship: A Guide for Organizational and Social Research. Oxford: Oxford University Press.

Walsham, G. (2006) Doing interpretive research. European Journal of Information Systems, 15(3), 320-30.

Weick, K.E. (1976) Educational organizations as loosely coupled systems. Administrative Science Quarterly, 21(1), 1-19.

Whyte, J. and Lobo, S. (2010) Coordination and control in project-based work: Digital objects and infrastructures for delivery. Construction Management and Economics, 28(6), 557-67.

Whyte, J. and Levitt, R. (2011) Information management and the management of projects. In: Morris, P., Pinto, J. and Söderlund, J. (eds.), Oxford Handbook of Project Management, Oxford University Press, Oxford, pp. 365-87.

Young, N., Jones, S., Bernstein, H., and Gudgel, J. (2009) The Business Value of BIM: Getting Building Information Modeling to the Bottom Line, McGraw Hill, New York, NY. 


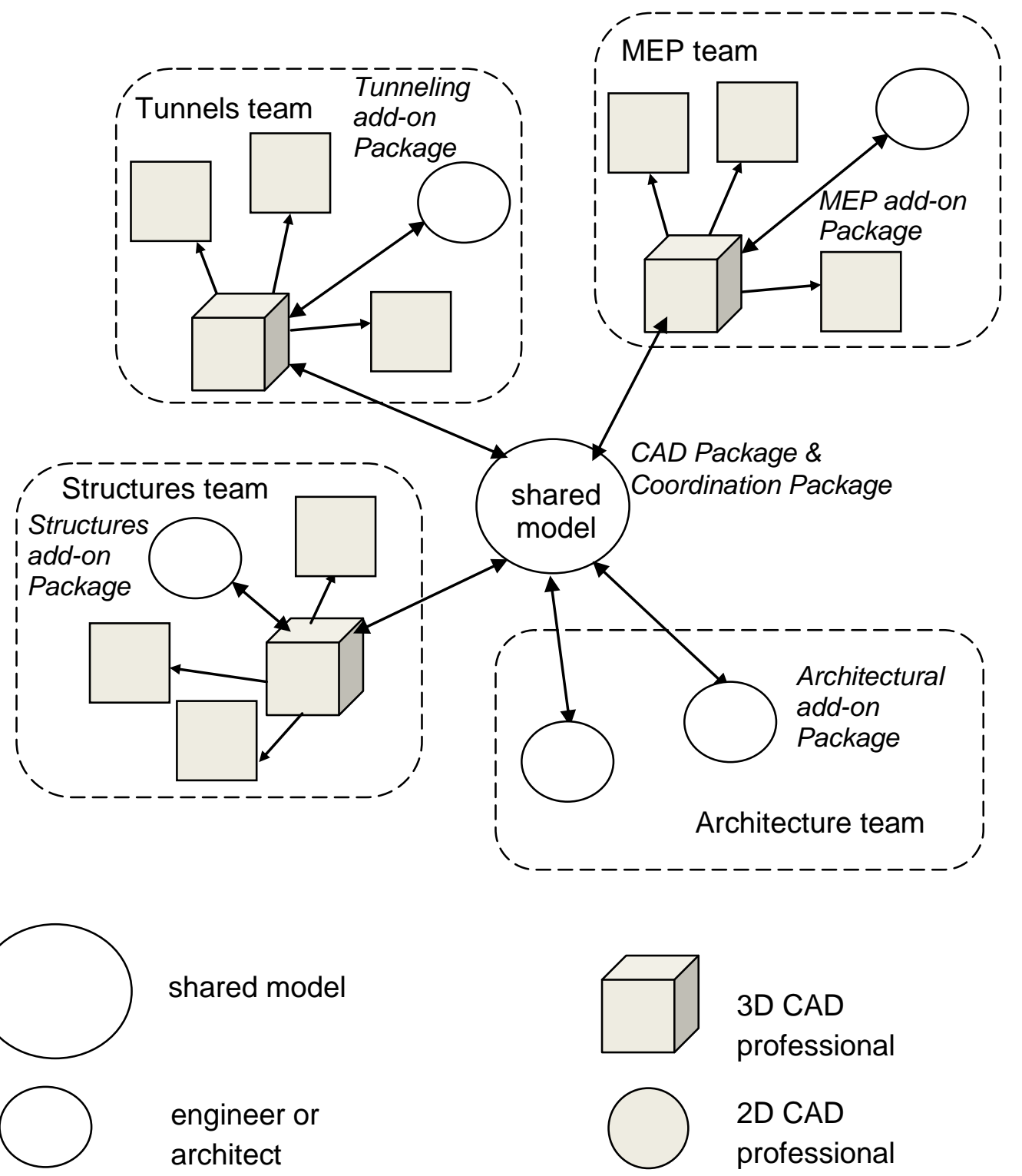

Figure 1: Different structure of responsibilities in the engineering sub-teams (structures, MEP and tunnels) and the architecture team involved in the station refurbishment project. 


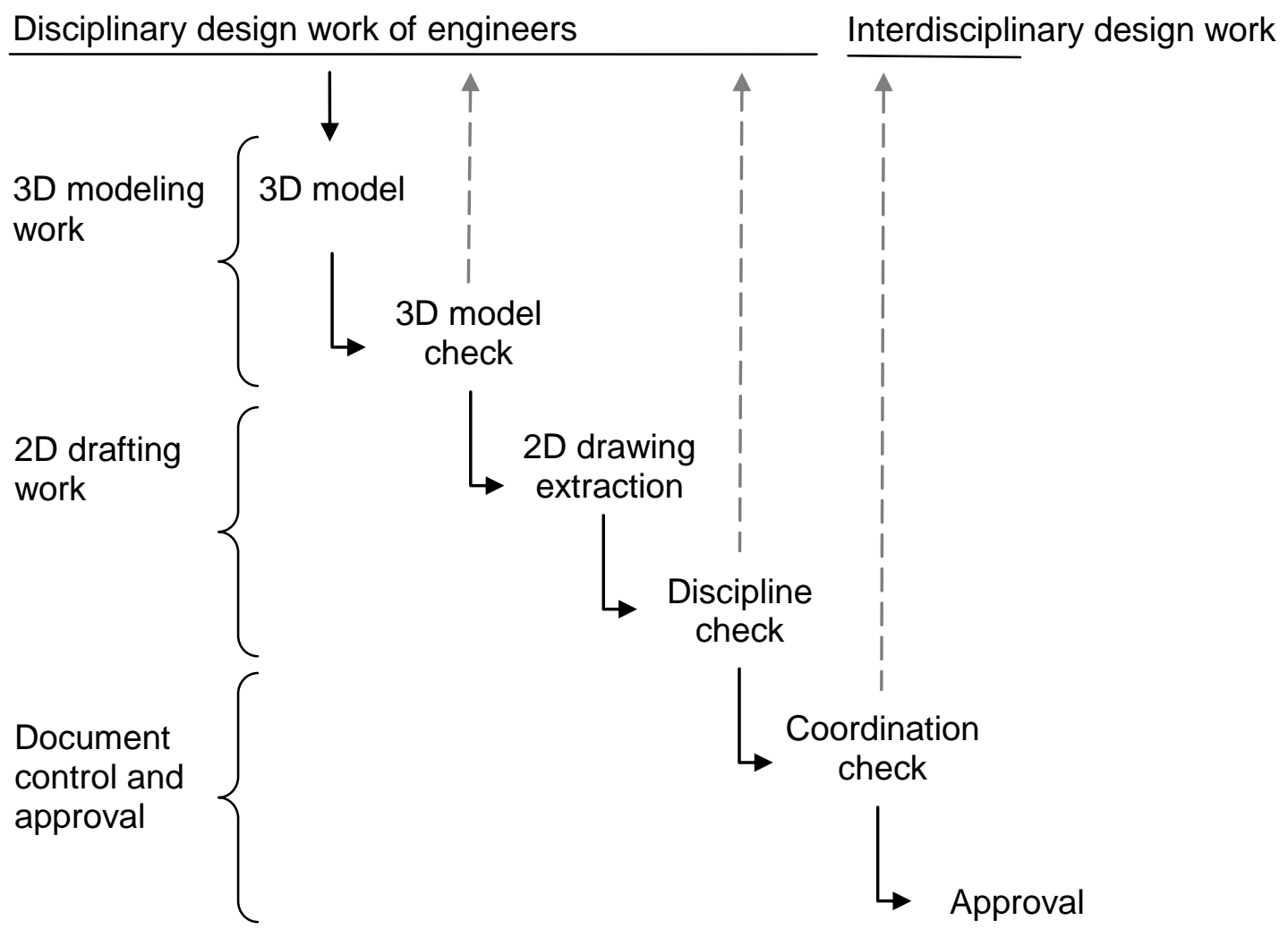

Figure 2: The design workflow from the 3D model to 2D coordination and approval in the station refurbishment project 